Human Behavior

in the Social

Environment

\title{
Investigating the Integrated Psychosocial Model of Criminal Social Identity (IPM-CSI) within a sample of community based youth offenders
}

\begin{tabular}{|r|l|}
\hline Journal: & Journal of Human Behavior in the Social Environment \\
\hline Manuscript ID & WHUM-2018-0139 \\
\hline Manuscript Type: & Original Article \\
\hline Keywords: & $\begin{array}{l}\text { Integrated Psychosocial model of a Criminal Social Identity (IPM-CSI), } \\
\text { Delinquent social identity, The Measure of Delinquent Social Identity, } \\
\text { Youth offenders }\end{array}$ \\
\hline \multicolumn{2}{c}{}
\end{tabular}

\section{SCHOLARONE" \\ Manuscripts}


Investigating the Integrated Psychosocial Model of Criminal Social Identity (IPM-CSI) within a sample of community based youth offenders 


\begin{abstract}
The current study aimed to explore the correlates of CSI in a single study, using the recently validated MDSI (Measure of Delinquent Social Identity). Path analysis was conducted among a sample of opportunistically selected youth offenders $(N=536$; age range from 12 to 17 years), separately for boys $(n=348 ; M$ age $=15.28$ years $)$ and girls $(n=188 ; M$ age $=15.23$ years $)$. Findings showed a positive significant relationship between interpersonal manipulation and ingroup affect $(\beta=.08)$ for boys, and a positive significant relationship between interpersonal manipulation and in-group ties $(\beta=.21)$ for girls. Among boys, the findings revealed a negative significant relationship between self-esteem and cognitive centrality $(\beta=-.13)$. For girls only, a negative significant relationship was identified between living with parents and associating with criminal friends $(\beta=-.20)$. Limitations and advantages, including practical implications, of the current research are discussed, highlighting directions for future research.
\end{abstract}

Key Words: Integrated Psychosocial model of a Criminal Social Identity (IPM-CSI); Delinquent social identity; The Measure of Delinquent Social Identity; Path analysis; Youth offenders 
Investigating the Integrated Psychosocial Model of Criminal Social Identity (IPM-CSI) within a sample of community based youth offenders

\section{Introduction}

Researchers argue that identity comprises of meanings that an individual assigns to the roles they play in different social contexts (Stryker \& Burke, 2000), which is in line with the psychosocial stance the present paper holds. Early theories of identity focus on the psychosocial development of individuals and how social experiences impact upon this (Erikson, 1963). Expanding on this, Turner (1982) asserts that there are two types of identity; personal and social. Personal identity refers to the unique features of individuals that separates them from one another, whereas social identity is concerned with social interactions with others, developing similarities with others and acknowledging self-perception as a member of certain social groups (Vryan, Adler, \& Adler, 2003).

The Social Identity Theory (SIT; Tajfel \& Turner, 1979) focuses on how one's knowledge of membership in a social group and the value and emotional significance of the group membership contributes towards the development of an individual's self-concept (Tajfel, 1978). The SIT is underpinned by the notion that humans feel the need to have a sense of belonging (Baumeister \& Leary, 1995) and, through developing group membership, group behaviours are instilled. The SIT denotes that individuals strive to achieve and maintain a high sense of self-esteem, which is enhanced by portraying positive evaluations about the social group to which they belong (Rubin \& Hewstone, 1998). However, achieving a pro-social identity is not always possible (e.g., due to 
the lack of pro-social peers with whom one can connect) and may result in the development of an anti-social/criminal identity (Jackson, Sullivan, Harnish \& Hodge, 1996).

Boduszek and Hyland (2011) posited that a criminal social identity (CSI) is formed through group membership with other offenders, enduring the same process as highlighted in the social identity theory. Drawing on Cameron's (2004) research into social identity, Boduszek, Adamson, Shevlin, and Hyland (2012a) proposed that a criminal social identity consists of three dimensions: cognitive centrality, in-group affect and in-group ties. Cognitive centrality refers to the psychological prominence and importance of belonging to the social group based on the individual's beliefs about themselves. Thus high cognitive centrality scores indicate that the individual's identity as part of a criminal group is seen as central to their self-concept and the individual places importance on their role within the group. Subsequently they are more likely to adhere to group norms, regardless of the physical presence of other group members. In-group affect relates to the positive feelings the individual has towards the group and its members. Thus, high in-group affect scores can reflect a reduced anxiety from being part of a group. In-group ties dimension relates to the emotional connection one has with other members of the group. Alike high cognitive centrality scores, individuals possessing high in-group ties scores tend to display behaviours that are characteristic of the group.

Focus is therefore drawn to the underlying reasons for generating an identity with a criminal group, pertinent in targeting the risk factors most likely to lead to criminal group membership and thus criminal behaviour. Providing a theoretical perspective of CSI (Boduszek \& Hyland, 2011), Boduszek, Dhingra and Debowska (2016a) proposed the Integrated Psycho-Social Model of CSI (IPM-CSI), which is based upon previously empirically tested theories of the origins of CSI. The IPM-CSI explains the underlying reasons for the development of CSI, based upon four sets of 
concepts: (1) an identity crisis that results in weak bonds with society, peer rejection, and is associated with poor parental attachment and supervision; (2) exposure to a criminal/antisocial environment in the form of associations with criminal friends before, during, and/or after incarceration; (3) a need for identification with a criminal group in order to protect one's selfesteem and (4) the moderating role of personality traits in the relationship between criminal/antisocial environment and the development of CSI.

\section{Identity Crisis}

The concept of an 'identity crisis' refers to children being unable to achieve pro-social group membership resulting in feelings of frustration and stress (Agnews, 1993; Erikson, 1959; Higgins, 1987; Waterman, 1985; Salovey \& Rodin, 1984). It is believed that the weak parental attachment and a lack of parental supervision during childhood can have an adverse impact on pro-social behaviour due to a lack of social control (Boduszek, Adamson, Shevlin, Hyland \& Dhingra, 2014a; Hirschi, 1969; Ingram, Patchin, Huebner, McCluskey, \& Bynum, 2007; Shaw \& Scott, 1991; Simons, Whitbeck, Conger, \& Conger 1991). Although no direct relationship has been identified between parental attachment and CSI in an adult population, an indirect negative relationship between parental supervision and all three aspects of CSI has been acknowledged (Boduszek, Adamson, Shevlin, Mallett, \& Hyland., 2012b). In addition, Boduszek et al., (2012b) identified that a lack of parental supervision also correlates with associating with other criminals.

Being part of a social group, albeit pro- or anti-social, leads to individuals adapting, or completely changing, their views, attitudes and behaviours to fit with the group they now identify with (Hogg, 2001). Drawing on the Self-Categorisation Theory (SCT; Turner, Hogg, Oakes, Reicher, \& Wetherell, 1987; Turner, Oakes, Haslam, \& McGarty, 1994), one's social identity becomes salient when individuals categorise themselves as a member of that group. Disparities 
between social groups thus become more distinct and members of anti-social groups experience rejection from their pro-social peers, further enhancing identity with the anti-social group (Thornberry, Krohn, Lizotte, \& Chard-Wierschem, 1993). There are numerous studies in support of a link between peer rejection and anti-social behaviour (e.g., Bagwell, 2004; Laird, Jordan, Dodge, Pettit, \& Bates, 2001; Rubin \& Hewstone, 1998), however there is scant research surrounding the direct and indirect relationship with CSI. Rejection from peers has been linked to lowered self-esteem with a higher likelihood of engaging in anti-social behaviour (Downs \& Rose, 1991; Juvonen, 1991; Parker \& Asher, 1987).

\section{Exposure to criminal/anti-social environment}

In line with Aker's $(1979 ; 1985)$ Differential Reinforcement Theory, exposure to an antisocial/criminal environment, particularly during the process of an identity crisis, is more likely to lead to associations with offenders, influencing criminal attitudes and cognitions and leading to criminal behaviour (Andrews \& Kandel, 1979; Holsinger, 1999; Mills, Kroner, \& Forth, 2002; Mills, Anderson, \& Kroner, 2004). Studies surrounding this concept explore criminal associations, prisonization/time spent in prison and/or criminal attitudes. Research suggests that associating with other criminals is positively related to all three facets of CSI (Boduszek et al., 2012b; Boduszek, Dhingra \& Debowska, 2016b; Spink et al., 2018). Boduszek et al (2012b) identified an indirect relationship between parental supervision and CSI, through criminal associations. Sherretts, Boduszek and Debowska (2016) found that psychopathy moderates the relationship between criminal associations and in-group ties. Studies have shown that the more time spent in prison the higher the likelihood of the development of certain facets of CSI (Boduszek \& Debowska, 2017; Walters, 2003). Whilst prisonization ("the adoption of the folkways, mores, customs, and general culture of the inmate subculture", Clemmer, 1940, p. 270) was shown to 
increase cognitive centrality and in-group ties (Boduszek \& Debowska, 2017), a longitudinal study by Walters (2003) revealed that cognitive centrality only increased for those serving their first prison sentence. Furthermore, some researchers have only found an indirect relationship whereby psychopathy has moderated the relationship between time spent in prison and CSI (Boduszek et al., 2016b; Sherretts et al., 2016). Although research identifies a relationship between CSI and criminal attitudes, findings are inconsistent as to which CSI facets are related with this external criterion (Boduszek, Adamson, Shevlin \& Hyland, 2012c; Boduszek, Adamson, Shevlin, Hyland, \& Bourke, 2013).

\section{A need for identification with a criminal group in order to protect one's self-esteem}

Drawing on the Social Comparison Theory (Festinger, 1954), group members compare themselves to their respective group members (in-group) and other social groups' members (outgroup) in order to acknowledge their social group as more favourable and subsequently increase positive self-evaluations (Ellemers, Kortekaas, \& Ouwerkerk, 1999; Tajfel \& Turner, 1979). Rejection from peers has been linked to lowered self-esteem and a higher likelihood of engaging in anti-social behaviour (Downs \& Rose, 1991; Juvonen, 1991; Parker \& Asher, 1987). However, individuals within anti-social groups may increase their self-esteem by adopting a 'social creativity strategy', whereby they compare their group to more deprived/lower class groups to perceive their group as more positive, in turn allowing for positive evaluations (Tajfel, 1978). In line with this, research suggests that the formation of criminal cognitions (cognitive centrality) is associated with negative self-evaluations, while loyalties (in-group ties) and emotional connections (in-group affect) to the group are associated with positive self-evaluations (Boduszek et al., 2012b; Boduszek \& Debowska, 2017). 


\section{The moderating role of personality traits in the relationship between criminal/antisocial environment and the development of CSI}

The IPM-CSI model elucidates that the relationship between environmental factors and CSI may be moderated by an individual's personality traits. Within the model, a special emphasis is placed on psychopathic personality traits. The prevalence of psychopaths within the prison service (9$30 \%$ ) has been noted to be higher than within the general population (1-3\%) (Nicholls, Ogloff, Brink \& Spidel, 2005; Vitale, Smith, Brinkley \& Newman 2002; Strand \& Belfrage, 2005). Therefore, it is not surprising that psychopathy is a widely researched topic in the area of offending behaviour (Declercq, Willemsen, Audenaert, \& Verhaeghe, 2012; Gendreau, Goggin, \& Smith, 2002; Häkkänen \& Hare, 2009; Laurell \& Dåderman, 2007; Salekin, Rogers, \& Sewell, 1996). Psychopathy has been characterised by interpersonal (e.g. selfishness, grandiose, lying and manipulative behaviour), affective (e.g. lacking empathy/remorse) and behavioural (impulsivity, violating social norms and expectations) traits (Hare, 2003). The callous affect facet (lack of remorse, lack of empathy, shallow; Hare \& Newman, 2008) of psychopathy has been shown to act as a moderator between criminal associations and in-group ties (Sherretts et al., 2016). Sherretts et al. also identified that the antisocial behaviour facet of psychopathy correlates with all three aspects of CSI, whereas erratic lifestyle and interpersonal manipulation aspects of psychopathy positively associate with in-group ties. The researchers theorised that individuals utilise interpersonal manipulation skills in order to simulate changes in identity and, using impression management, elicit positive evaluations from others, leading to the maintenance of positive selfesteem (Goffman, 1963, 1990). Based upon this, offenders with low levels of interpersonal manipulation could be expected to have low self-esteem; however, this remains to be empirically tested. 
Hare's (2003) concept of psychopathy has been critiqued for including behavioural factors - erratic lifestyle and antisocial/criminal behaviour - as they seem to be an outcome of psychopathy, not an integral part of it (see Boduszek \& Debowska, 2016 for a review). Since criminal behaviour can also be an outcome of CSI, the use of a psychopathy measure indexing criminal/antisocial behaviour as a moderator in the IPM-CSI model would be tautological. In considering the above criticisms, Boduszek, Debowska, Dhingra, and DeLisi (2016c) developed a four-factor, personality-based model of psychopathy consisting of affective responsiveness (low empathy and emotional shallowness), cognitive responsiveness (emotional awareness of others' emotional states and an ability to engage with others' emotionally on a cognitive level), interpersonal manipulation (superficial charm, grandiose beliefs and calculating behaviour) and egocentricity (self-centredness). To date, research testing the associations between this personality-based psychopathy model and CSI is missing. Furthermore, all of the above-cited studies in the area of CSI and psychopathic traits focused on adult populations. Although personality is in the state of flux in childhood and adolescence and, as such, youngsters cannot be diagnosed with a personality disorder, recognising problems early on could be beneficial to designing appropriate interventions (Frick, 2007). In the context of IPM-CSI, targeting malfunctioning personality traits related to CSI development can result in improved outcomes for youth at risk (i.e., those exposed to environmental risk factors for CSI). As such, empirical research testing associations between environmental and personality characteristics and CSI among adolescents may have important practical implications.

Research surrounding gender differences in psychopathy tends to be based upon Hare's (2003) concepts of psychopathy. In studying females, findings showed that correlations between interpersonal and affective facets of psychopathy and recidivism are positive and significant, 
whereas correlations between behavioural factors of psychopathy and recidivism are nonsignificant (Salekin et al., 1996). Gender differences have also been acknowledged in criminal social identity, suggesting that females are more likely to form stronger bonds and identification than males due to an increased desire to be accepted by other group members (Brown, Condor, Matthews, Wade, \& Williams, 1986; Kiesner, Cadinu, Poulin, \& Bucci, 2002; Newman, Loman, \& Newman, 2007). Providing additional support to female offenders, such as additional visits to maintain family bonds, was suggested as a practical implication by Sherretts et al. (2016), however, further research is required to support this notion.

Research concerned with exploring the elements of the IPM-CSI is predominantly based on imprisoned male adults (Boduszek et al., 2012b; Boduszek et al., 2012c; Boduszek et al., 2013; Boduszek \& Debowska, 2017; Walters, 2003), with scant research focussing on youth offenders (Boduszek et al., 2016b; Spink et al., 2018) and females (Sherretts et al., 2016; Spink et al., 2018). All but one piece of research (Spink et al., 2018) considers offenders who are imprisoned and there is a void in investigating the developments of CSI in community based offenders. As most of the research surrounding CSI is over five years old (Boduszek et al., 2012b; Boduszek et al., 2012c; Boduszek et al., 2013; Walters, 2003), limited studies utilise up to date measures (Boduszek \& Debowska, 2017; Spink et al., 2018). For example, only Boduszek and Debowska (2017) used a revised measure of CSI (MCSI-R; Boduszek \& Debowksa, 2017), whereas the older studies (Boduszek et al., 2012b; Boduszek et al., 2012c; Boduszek et al., 2013) administered the original CSI measure (MCSI; Boduszek et al., 2012a), which has been critiqued for lacking internal consistency among some participant samples and being too simplistic for such a complex psychological construct (Sherretts et al., 2016).

\section{The current study}


Although the IPM-CSI (Boduszek et al., 2016a) offers a comprehensive explanation of the development of CSI, research has not explored all of its elements in one single study. The main aim of the present research was to fill this void by testing the following associations: parental factors (parental rejection, parental attachment, parental supervision, presence of a parent/no parent) with criminal associations; parental factors (parental rejection, parental attachment, parental supervision, presence of a parent/no parent) with self-esteem; criminal associations with criminal attitudes; criminal associations with each DSI facet (cognitive centrality, in-group affect and in-group ties), self-esteem with each DSI facet (cognitive centrality, in-group affect and ingroup ties), and each psychoapthy facet (affective responsiveness, cognitive responsiveness, interpersonal manipulation and egocentricity) with each DSI facet (cognitive centrality, in-group affect and in-group ties). Since existing studies in the area are predominantly adult male based, the present study focused on a mixed gender sample of youth offenders in order to expand the existing scholarship. It is envisaged that this will have a valid contribution towards the development of psychological offender behaviour programmes.

\section{Method}

\section{Sample}

Using opportunistic sampling, the authors approached $N=624$ youth offenders in total and $N=536$ returned completed surveys (response rate $=85.9 \%$ ). The only inclusion criterion was that participants were currently serving a sentence with the YOT and were aged between 12 and 17 years old. Although the YOT engages with young persons from the age of 10, it was deemed that the nature of the questionnaires could cause some unnecessary discomfort or distress to those under the age of 12 and they may struggle to understand certain concepts. Thus, youths below the age of 12 were not given the opportunity to partake. There was no missing data, which is likely due to 
youth workers assisting youth offenders in the completion of the survey. Therefore, $N=536$ of youth offenders were included in the current analysis, comprising of $n=348(64.9 \%)$ males (age range from 12 to 17 years, $M=15.28, S D=1.10, M d n=15$, and Mode $=15)$ and $n=188(35.1 \%)$ females (age range from 12 to 17 years, $M=15.23, S D=1.19, M d n=15$, and Mode $=15$ ).

For males, 128 (36.8\%) participants were living with one parent, 90 (25.9\%) living in a care home, $60(17.2 \%)$ living with both parents, $36(10.3 \%)$ living in foster care, $18(5.2 \%)$ living with grandparents, $8(2.3 \%)$ living without parents and $8(2.3 \%)$ living with step parents. For females, 75 (39.9\%) participants were living with one parent, 47 (25\%) living in a care home, 26 (13.8\%) living with both parents, $18(9.6 \%)$ living in foster care, $16(8.5 \%)$ living with grandparents, $4(2.1 \%)$ living without parents and $2(1.1 \%)$ living with step parents.

\section{Procedure}

Authors in collaboration with the Youth Offending Team (YOT) chose five establishments within the Yorkshire area to take part in the research. The authors distributed self-report surveys to all establishments. The youth workers, trained by the authors, administered the surveys in their one to one sessions with the youth offenders. To minimise sampling bias and maximise the generalisability of findings, participants were encouraged to complete the survey in the presence of their youth worker. The likelihood of such was enhanced given an existing professional relationship, encouraging openness and honesty, between the youth offender and their youth worker. This also gave the youth offenders the opportunity to discuss the content of the survey which enabled youth workers to assist with any difficulties in reading and/or understanding the content and also address any safeguarding concerns. The youth offenders were provided with an information sheet, whereby the nature and purpose of the study was clarified, and a consent sheet informing of anonymous data collection and how to withdraw from the study. Given youth 
offenders' standing as a vulnerable population and that this took part in their YOT sessions there was potential that they may have felt compelled to participate. It was therefore made clear both in the consent form and verbally that participation was voluntary, without any form of reward.

\section{Measures}

The Measure of Delinquent Social Identity (MDSI; Spink et al., 2018) is adapted from the MCSI-R (Boduszek \& Debowska, 2017). The MDSI consists of 15 items scored on a 4-point Likert scale $(1=$ completely disagree to $4=$ completely agree). Scores range from 15 to 60 , with higher scores suggesting enhanced levels of delinquent social identity. The scale consists of three subscales: cognitive centrality (five items) subscale measures the psychological salience of a delinquent's group identity; in-group affect (five items) subscale measures a delinquent's felt attitude toward other in-group criminals; and in-group ties (five items) subscale assesses the level of personal bonding with other delinquents. Good internal reliability was reported with the current sample (cognitive centrality $=.86$, in-group affect $=.73$, in-group ties $=.86)$.

Peer Rejection (Mikami, Boucher, \& Humphreys, 2005). A 4-item selfreport/retrospective inventory with a 5-point Likert scale response format ranging from a positive answer (5) to a negative (1) with one reverse-scored question. Thus, the possible total score can range from a minimum of 4 to a maximum of 20, with higher scores reflecting more positive peer relations and lack of rejection. Participants are asked to indicate the amount of peers they like versus dislike in the class they attend (Sample question: "How many students in your class did you get along with?"). In addition, they had to estimate the amount of peers who respected them versus those who tend to picked on them (Sample question: "How many students in your class teased you, put you down, or picked on you?"). Internal reliability $=.74$. 
Parental attachment (Ingram et al., 2007). A 9-item self-report measure of the nature of the positive and negative relationship between offenders and their parents. Participants were asked how often they felt each statement was true (e.g., positive relationship "They support my goals and interests"; negative relationship "They ignore what I have to say"). Answers were based on a 4-point Likert type scale ranging from 1 (not at all) to 4 (very much). Thus, the possible total score can range from a minimum of 9 to a maximum of 36, with higher values indicating stronger parental attachment. Internal reliability $=.97$.

Parental Supervision (Ingram et al., 2007). A 6-item self-report instrument including questions regarding parental knowledge about range of aspects of offenders' lives when they were at the school age. These aspects included parental knowledge of participants' close friends, friends' parents and school teacher; what they were doing with friends; who they were with when they were not at home; and what they were doing at school. Answers were based on a 4-point Likert type scale ranging from 1 (almost nothing) to 4 (almost everything). Thus, the possible total score can range from a minimum of 6 to a maximum of 24 , with higher scores indicating greater indirect parental supervision. Internal reliability $=.96$.

The Measure of Criminal Attitudes and Associates (MCAA; Mills \& Kroner, 1999). A two-part self-report measure of associations with criminal friends and criminal thinking style. For the purpose of this study only Part A will be used. Part A of the measure intends to quantify criminal associations. Participants are asked to recall three individuals with whom they spent most of their time and then answered four questions regarding the degree of criminal involvement of their associates: (a) "Has this person ever committed a crime?", (b) "Does this person have a criminal record?", (c) "Has this person ever been to prison?", and (d) "Has this person tried to involve you in a crime?". This measure is referred to as "Criminal Friend Index" calculated by 
assigning 1 through 3 to the amount of time spent with each friend $(1=$ not a lot, $2=$ quite a lot, 3 $=$ lots of time). That number is then multiplied by the number of "yes" responses to the four questions of criminal association. All answers are summed as the Criminal Friend Index.

Attitudes towards in-group and out-group members. A 5-item self-report measure on attitudes towards in-group and out-group members, measured on a 4-point Likert scale ranging from1 (completely disagree) to 4 (completely agree). Thus, the possible total score can range from a minimum of 5 to 20 , with questions 2, 4 and 5 scores reversed. Lower scores indicate stronger attitudes towards offenders/offending. Internal reliability $=.71$.

Self-Esteem Measure for Delinquents (SEM-D) is adapted from the SEM-C (Debowska, Boduszek, \& Sherretts, 2017). The Self-esteem measure for criminals is an 8-item self-report measure assessing self-esteem among incarcerated adult populations. The measure consists of two subscales: prison-specific self-esteem (4 items), looking at self-esteem in a specific context, and personal self-esteem (4 items), inquiring into self-esteem in a context-free manner. Responses are indexed on a 4 -point Likert scale $(1=$ never, $4=$ always $)$. The items of the measure were adapted to suit the non-prison population and youth age group. Due to this, one of the items was removed as it was not deemed suitable for the sample population. This resulted in a 7-item self-report measure assessing self-esteem among delinquent youths. The 4-point Likert scale $(1=$ never, $4=$ always) remained for responses to be recorded. Scores for the total scale range from 7 to 28 , with higher scores indicating increased levels of self-esteem. Internal reliability $=.80$.

Psychopathic Personality Traits Scale (PPTS; Boduszek et al., 2016c) The PPTS is a selfreported 20-item measure designed to assess psychopathic traits in forensic and non-forensic populations. The scale was developed to measure four factors labelled affective responsiveness (Factor 1), cognitive responsiveness (Factor 2), interpersonal manipulation (Factor 3), and 
egocentricity (Factor 4). Each subscale consists of five items measured using agree (1) and disagree (0) format (i.e., a trait is either present or absent). Scores range from 0 to 20 , with higher scores indicating elevated levels of psychopathic personality traits (i.e., greater egocentricity and interpersonal manipulation and increased deficits in affective and cognitive responsiveness). The affective responsiveness subscale is made up of items concerning characteristics of low empathy and emotional shallowness. Cognitive responsiveness subscale measures the ability to understand others' emotional states, mentally represent another person's emotional processes, and engage with others' emotionally at a cognitive level. The interpersonal manipulation subscale measures characteristics such as superficial charm, grandiosity, and deceitfulness. Finally, egocentricity subscale assesses an individual's tendency to focus on one's own interests, beliefs, and attitudes. Internal reliability for affective responsiveness $=.71$, cognitive responsiveness $=70$, interpersonal manipulation $=79$, and egocentricity $=72$.

Demographics Questionnaire. Further to the above, the following data was obtained; age, gender and living condition (with parent(s) / without parents (i.e. on my own).

\section{Analytical procedure}

An independent samples t-test was used to compare mean scores between males and females on all continuous variables. Cohens d (Cohen, 1988) was used to calculate the size of the effect. According to Cohen (1988) a small effect is 0.2 a medium effect is 0.5 and a large effect is 0.8 and above.

In the current study the DSI model was tested via path analysis in MPlus version 7.11. The following statistics were used to assess the fit between the data and pre-established theoretical model: Chi Square $\left(\chi^{2}\right)$, Tucker Lewis Index (TLI; Tucker \& Lewis, 1973), Root-Mean-Square Error of Approximation (RMSEA; Steiger, 1990) with 90\% confidence interval (90\% CI), Root 
Mean-Square Residual (RMSR) and Comparative Fit Index (CFI; Bentler, 1990). For a good model, the Chi square should be non-significant (Kline, 2005) and CFI and TLI values above .95 (Hu \& Bentler 1999; Vandenberg 2002). However, CFI and TLI, values above .90 indicate adequate fit (Bentler 1990; Hu \& Bentler 1999). RMSEA and RMSR values less than .05 suggest good fit and values up to .08 indicate reasonable errors of approximation in the population (Browne \& Cudeck 1989). Regression weights indicate the direction and strength of the relationship with higher values representing a stronger relationship.

\section{Results}

Descriptive statistics, including means $(M)$ and standard deviations $(S D)$ for the three MDSI factors, Criminal friend index, Criminal Attitudes, Self-esteem, Peer Rejection, Parental Attachment, Parental Supervision and the four PPTS factors are presented in Table 1.

\section{(Please insert Table 1 here)}

An independent t-test was conducted to compare the CFI, Criminal Attitudes, Self-esteem, Peer Rejection, affective responsiveness, cognitive responsiveness, interpersonal manipulation and egocentricity scores of males and females. There was a significant difference between both groups on CFI scores, $t(534)=1.95, p<.05$, with males $(M=19.72, S D=5.54)$ scoring higher than females $(M=18.72, S D=5.85)$. The magnitude of the differences in the means of CFI (mean difference $=.99,95 \% \mathrm{CI}:-.01$ to 2$)$ was small $(d=.18)$. There was a significant difference between both groups on cognitive responsiveness scores, $t(534)=-1.93, p<.05$, with females $(M=2.78$, $S D=1.34)$ scoring higher than males $(\mathrm{M}=2.55, \mathrm{SD}=1.28)$. The magnitude of the differences in the means of cognitive responsiveness (mean difference $=-.23,95 \% \mathrm{CI}:-.46$ to .004 ) was small $(d=.18)$ 
Due to some significant differences between males and females being found path analysis was conducted separately for males and females. The fit of the proposed model for males was adequate, $\chi^{2}(34)=65.58, p<.001, \mathrm{CFI}=.95, \mathrm{TLI}=.90, \mathrm{RMSEA}=.07(90 \% \mathrm{CI}=[.05, .10])$, $\operatorname{RMSR}=.05$. The fit of the proposed model for females was adequate, $\chi^{2}(34)=64.10, p<.01$, $\mathrm{CFI}=.90, \mathrm{TLI}=.80, \mathrm{RMSEA}=.10(90 \% \mathrm{CI}=[.06, .13]), \mathrm{RMSR}=.06$. Table 2 presents the direct path regression weights for males and females. Figure 1 present the direct paths for males and figure 2 present the direct paths for females.

\section{(Please insert Table 2 here) \\ (Please insert Figure 1 here) \\ (Please insert Figure 2 here)}

As can be observed, there was a significant positive correlation between egocentricity and cognitive centrality for both males $(\beta=.84)$ and females $(\beta=.80)$. There was a significant positive correlation between egocentricity and in-group affect for both males $(\beta=.87)$ and females $(\beta=$ .82). There was a significant negative correlation between egocentricity and in-group ties for both males $(\beta=-.25)$ and females $(\beta=-.28)$. There was a significant positive correlation between interpersonal manipulation and in-group affect for males $(\beta=.08)$, however, interpersonal manipulation significantly correlated with in-group ties for females $(\beta=.21)$. There was a significant negative correlation between cognitive responsiveness and in-group ties for both males $(\beta=-.25)$ and females $(\beta=-.18)$. There was a significant positive correlation between affective responsiveness and in-group ties for females $(\beta=.25)$ but no significant relationships were identified between affective responsiveness and any of the three MDSI factors for males. 
There was a significant positive correlation between CFI and in-group ties for males ( $\beta=$ .15) but no significant relationships were identified between CFI and DSI for females. There was a significant negative correlation between self-esteem and cognitive centrality for males $(\beta=-$ .13). However, a significant positive correlation was identified between self-esteem and in-group ties for both males $(\beta=.42)$ and females $(\beta=.50)$.

There was a significant negative correlation between parental supervision and CFI for both males $(\beta=-.19)$ and females $(\beta=-.19)$. There was a significant negative correlation between living with a parent and CFI for females $(\beta=-.20)$.

\section{Discussion}

The Integrated Psychosocial Model of Criminal Social Identity (IPM-CSI; Boduszek et al., 2016a) was introduced as a theoretical explanation for the development of criminal social identity (CSI), however, research supporting this framework is scarce (Boduszek et al., 2012c; Boduszek et al., 2013; Boduszek et al., 2016b; Sherretts et al., 2016). The present research is the first study to consider all of the components of the IPM-CSI in a single study. Further, research surrounding CSI has mainly focussed on adult male populations using a measure of CSI (MCSI; Boduszek et al., 2012a) devised for adults (Boduszek et al., 2012b; Boduszek et al., 2012c; Boduszek et al., 2013). The present study aimed to fill the void in research by utilising a recently validated measure of delinquent identity devised for youth offenders (MDSI; Spink et al., 2018) in a sample of mixed gender youth offenders. The findings are also impactive due to identifying the differences in the correlates of delinquent social identity (DSI) between girls and boys who offend. The main gender differences identified within the study surround the effect of psychopathy, criminal friend index (CFI) and self-esteem on DSI, and the effect of presence of a parent on CFI. 
First, we tested the effect of four psychopathic personality traits (affective responsiveness, cognitive responsiveness, interpersonal manipulation, and egocentricity) on DSI dimensions (cognitive centrality, in-group affect, and in-group ties). Interpersonal manipulation was found to significantly correlate with in-group affect for boys and with in-group ties for girls. This suggests that male youth offenders with increased grandiosity and manipulative tendencies are more likely to develop emotional attachments with other delinquents, whereas girls with such tendencies are more likely to be loyal towards other delinquents. The latter is in support of research using mixedgender samples (Sherretts et al., 2016), despite such research using a measure of psychopathy based on Hare's (2003) concepts (Paulhus, Newman, \& Hare, 2015). Sherretts et al. (2016) proposed that the correlation between interpersonal manipulation and in-group ties is falsified through the individual influencing others' perceptions in a bid to increase their own self-esteem. However, current findings show that girls have marginally higher self-esteem scores than boys suggesting that this relationship would be expected more in boys, yet a weak non-significant correlation was identified between interpersonal manipulation and in-group ties among boys. It is suggested that future research considers the moderating effect of self-esteem on the relationship between interpersonal manipulation and in-group ties.

Affective responsiveness was shown to significantly positively correlate with in-group ties for girls. Among boys, the relationship between affective responsiveness and DSI factors was statistically non-significant. This indicates that female youth offenders who lack affective empathy are more likely to develop loyal relationships with youth offenders. This is in line with prior research utilising a mixed-gender sample which found that the relationship between criminal associations and in-group ties was moderated by high levels of callous affect (i.e., a construct characterised by low empathy) (Sherretts et al., 2016). A stronger social identity has been 
associated with the development of group norms in terms of behaviours and attitudes (Hogg, 2001; Van Veelen, Hansen, et al., 2013). For example, criminal groups display rule breaking / illegal behaviour. It could therefore be predicted that possessing a strong delinquent social identity would result in delinquent behaviours by group members. Previous research indicates that females with deficits in affective traits are more likely to reoffend (Salekin et al., 1996) and the present research shows a link between affective traits and delinquent social identity. Thus, it could be suggested that there is a link between personality, delinquent social identity and delinquent behaviour. This notion is also supported by research indicating that individuals, particularly youth offenders, are more likely to offend if they lack victim empathy (Eysenck \& McGurk, 1980). Further research should be directed to explore the moderating effect of in-group ties on the relationship between affective responsiveness and reoffending.

Another psychopathy factor, egocentricity, was shown to have a positive effect on cognitive centrality and in-group affect for both boys and girls. This result indicates that youth offenders who centralise their own beliefs, attitudes and interests are more likely to have an increased identification and sense of belonging with other delinquents. One possible explanation of this finding is that individuals with increased egocentric traits are likely to treat others with similar attitudes and outlook as an extension of self, resulting in positive feelings towards in-group members. However, as indicated by the finding that egocentricity forms a negative association with in-group ties, male and female youth offenders who tend to focus on their own beliefs, attitudes and interests are less likely to show loyalty towards other delinquents. This further highlights the self-serving function of the positive feelings towards in-group members.

The model for boys did not differ greatly from the model for girls in respect of cognitive responsiveness. More specifically, cognitive responsiveness was shown to negatively affect in- 
group ties, indicating that youth offenders who are able to engage with others emotionally at a cognitive level have decreased loyalty towards other youth offenders. As research surrounding psychopathy and CSI has focussed on Hare's (2003) model of psychopathy, which does not distinguish between affective and cognitive components of responsiveness to others (e.g., Sherretts et al., 2016), it is difficult to compare the current result with prior research findings. In considering the differential associations between affective and cognitive responsiveness and DSI dimensions demonstrated in the present investigation, it is recommended that more future research in the area employs PPTS to assess psychopathy.

The present research indicates that interventions should target different psychopathic personality traits among girls and boys in order to decrease the likelihood of developing a delinquent social identity and, in turn, committing offences. For example, interventions for boys should focus on reducing grandiosity and manipulative behaviours in order to prevent or reduce positive feelings towards offending groups and other offenders. Interventions for girls should target increasing empathic concern for others in order to prevent or reduce emotional connections towards other offenders. For both genders, interventions should focus on increasing selflessness to prevent or reduce criminal cognitions and positive feelings towards other offenders.

CFI was shown to significantly correlate with in-group ties for boys but a non-significant relationship was identified between CFI and DSI for girls indicating that associations with criminal friends may increase the loyalty towards other delinquents for boys only. This is in line with previous research focussing on male samples (Boduszek et al., 2012b; Boduszek et al., 2016b). It may be that interventions targeting reducing criminal associations would be particularly beneficial to boys, however, further research is required to support this. 
Self-esteem was positively correlated to in-group ties for boys and girls, but also negatively correlated to cognitive centrality in boys. Although in light of this finding it appears that interventions aimed at increasing self-esteem would be especially beneficial for boys, care must be taken when designing such programmes because they may also have a negative impact on other aspects of delinquent social identity. For example, in line with existing research (Boduszek et al., 2012b; Boduszek \& Debowska, 2017), the present research shows that both boys and girls with higher levels of self-esteem are more likely to develop loyal relationships with other youth offenders. It is therefore important to acknowledge the strengths and weaknesses of increasing self-esteem in interventions. Although previous theories (Differential Reinforcement Theory; Aker's, 1979; 1985) suggest that associations with criminal friends stem from exposure to a criminal environment during the process of an identity crisis when self-esteem levels are lower (Downs \& Rose, 1991; Juvonen, 1991; Parker \& Asher, 1987), the present findings open up the opportunity to explore whether boys and girls have different experiences during the identity crisis and whether the onset of such varies between genders. A longitudinal study would also allow the temporal relationship between the three factors to be explored to establish whether delinquent social identity increases or decreases self-esteem to support or contrasts with existing theory (Social Comparison Theory; Festinger, 1954) and research (Ellemers et al., 1999; Juvonen, 1991; Tajfel, 1978).

The model for boys did not differ from the model for girls in respect of the relationship between parental supervision and CFI. In line with existing research (Boduszek et al., 2012b) the present findings revealed a significant negative correlation between parental supervision and CFI indicating that the involvement of parents in childhood decreases the likelihood of developing criminal friends. This further supports Boduszek et al. (2012b) who emphasised that parental 
supervision has more importance in the relationship with offending than parental attachment. In addition, the presence of a parent during childhood had a negative effect on CFI but only for girls. Thus, living with a parent during childhood decreases the likelihood of developing friendships with delinquents among girls. This highlights the importance of providing support in sustaining living conditions with at least one parent among girls in particular.

The present study is not without its limitations which should be considered when noting the practical implications. A cross-sectional study design was implemented which restricted the ability to test the temporal order of the IPM-CSI. Longitudinal studies are therefore required to offer support to the temporal order. The sample consisted of youth offenders in the community within the Yorkshire area and so future research should explore whether the present results are generalisable across communities and settings. The present study aimed to limit response bias by encouraging participants to undertake the self-report measures in the presence and with the assistance of their youth offender worker. Although this would limit some of the response bias, it did not eradicate it, as some participants chose to complete the survey by themselves.

It is envisaged that, by contributing to the existing literature, the present research will allow advancements to be made within offender behaviour programmes. It is already evident that some offender behaviour programmes, for example Juvenile Enhanced Thinking Skills (JETS), incorporate cognitive behavioural skills related to DSI, such as managing criminal associates (negative influences). However, as the present study has identified, there are further specific areas that require targeting and this may differ depending on gender. The current findings provide empirical support for gender specific offender behaviour programmes. 


\section{References}

Agnew, R. (1993). Why do they do it? An examination of the intervening mechanisms between 'social control' variables and delinquency. Journal of Research in Crime and Delinquency, $30,245-266$.

Akers, R. (1985). Deviant behaviour: A social learning approach. Belmont: Wadsworth.

Akers, R., Krohn, M., Lonn, L., \& Radosevich, M. (1979). Social learning and deviant behaviour: A test of general theory. American Sociological Review, 44, 636-655.

Andrews, K., \& Kandel, D. (1979). Attitude and behavior: A specification of the contingent consistency hypothesis. American Sociological Review, 44:298-310.

Bagwell, C. L. (2004). Friendships, peer networks, and antisocial behavior. In J. B. Kupersmidt \& K. A. Dodge (Eds.), Decade of behavior. Children's peer relations: From development to intervention (pp. 37-57). Washington, DC, US: American Psychological Association. http://dx.doi.org/10.1037/10653-003

Baumeister, R. F., \& Leary, M. R. (1995). The need to belong: Desire for interpersonal attachments as a fundamental human motivation. Psychological Bulletin, 117(3), 497-529. doi:10.1037/0033-2909.117.3.497

Bentler, P. M. (1990). Comparative fit indices in structural models. Psychological Bulletin, 217, 238-246.

Boduszek, D., Adamson, G., Shevlin, M., \& Hyland, P. (2012a). Development and validation of a Measure of Criminal Social Identity within a sample of Polish recidivistic 
prisoners. Criminal Behaviour and Mental Health, 22(5), 315-324. doi: $10.1002 / \mathrm{cbm} .1827$.

Boduszek, D., Adamson, G., Shevlin, M., \& Hyland, P. (2012c). The role of personality in the relationship between criminal social identity and criminal thinking style within a sample of prisoners with learning difficulties. Journal of Learning Disabilities and Offending Behaviour, doi:10.1108/20420921211236771.

Boduszek, D., Adamson, G., Shevlin, M., Hyland, P., \& Bourke, A. (2013). The role of criminal social identity in the relationship between criminal friends and criminal thinking style within a sample of recidivistic prisoners. Journal of Behavior in the Social Environment, 23(1), 14-28. doi:10.1080/10911359.2013.737289.

Boduszek, D., Adamson, G., Shevlin, M., Mallett, J., \& Hyland, P. (2012b). Criminal social identity of recidivistic prisoners: The role of self-esteem, family and criminal friends. Journal of Police and Criminal Psychology, 28(1), 15-25. doi:10.1007/s11896-0129105-7.

Boduszek, D., \& Debowska, A. (2017). Further insights into the construct of criminal social identity: Validation of a revised measure in a prison population. The Journal of Forensic Psychiatry \& Psychology, 28(5), 694. doi:10.1080/14789949.2017.1318161.

Boduszek, D., Debowska, A., Dhingra, K., \& DeLisi, M. (2016c). Introduction and validation of the Psychopathic Personality Traits Scale (PPTS) in a large prison sample. Journal of Criminal Justice, 46, 9-17. doi:10.1016/j.jcrimjus.2016.02.004. 
Boduszek, D., Dhingra, K., \& Debowska, A. (2016b). The moderating role of psychopathic traits in the relationship between period of confinement and criminal $\quad$ social identity in a sample of juvenile prisoners. Journal of Criminal Justice, 44, 30- 35. doi:10.1016/j.jcrimjus.2015.11.005.

Boduszek, D., Dhingra, K., \& Debowska, A. (2016a). The Integrated Psychosocial Model of Criminal Social Identity (IPM-CSI). Deviant Behavior, 37(9), 1023-1031. http://dx.doi.org/10.1080/01639625.2016.1167433.

Boduszek, D., \& Hyland, P. (2011). The theoretical model of criminal social identity: Psycho-social perspective. International Journal of Criminology and Sociological Theory, 4(1), 604-615.

Boduszek, D., Adamson, G., Shevlin, M., Hyland, P., \& Dhingra, K. (2014a). Psycho-sociological investigation of criminal behaviour within a prison sample using retrospective data. The Howard Journal of Criminal Justice 53(1), 31-48. doi:10.1111/hojo.12044.

Brown, R., Condor, S., Mathews, A., Wade, G., \& Williams, J. (1986). Explaining intergroup differentiation in an industrial organization. Journal of Occupational Psychology, 59(4), 279-304.

Browne, M.W. \& Cudeck, R. (1989). Single sample cross-validation indices for covariance structures. Multivariate Behavioral Research, 24, 445-455

Cameron, J. (2004). A three factor model of social identity. Self and Identity, 3(3), 239-262. doi:10.1080/13576500444000047 
Cohen, J. (1988). Statistical power analysis for the behavioral sciences (2nd ed.). Hillsdale, NJ: Erlbaum.

Clemmer, D. (1966). The prison community. New York, NY: Holt, Rinehart, and Winston

Debowska, A., Boduszek, D., \& Sherretts, N. (2017). Self-esteem in adult prison population:

The development of the Self-Esteem Measure for Criminals (SEM-C). Deviant Behavior, 38, 1240-1251. doi: 10.1080/01639625.2016.1246034.

Declercq, F., Willemsen, J., Audenaert, K., \& Verhaeghe, P. (2012). "Psychopathy and predatory violence in homicide, violent, and sexual offences: Factor and facet relations", Legal and Criminological Psychology, Vol. 17 No. 1, pp. 59-74.

De Cremer, D., \& Van Vugt, M. (1999). Social identification effects in social dilemmas: A transformation of motives. European Journal of Social Psychology, 29, 871-893. http://dx.doi.org/10.1002/(SICI)1099-0992(199911)29:7 $\square 871:: A I D-E J S P 962 \square 3.0 . C O$

Downs, W. R., \& Rose, S. R. (1991). The relationship of adolescent peer groups to the incidence of psychosocial problems. Adolescence, 26(102), 473.

Ellemers, N., Kortekaas, P., \& Ouwerkerk, J. W. (1999). Self-categorisation, commitment to the group and group self-esteem as related but distinct aspects of social identity. European Journal of Social Psychology, 29(23), 371-389. doi:10.1002/(SICI)10990992(199903/05)29:2/3<371::AID-EJSP932>3.0.CO;2-U

Erikson, E. H., Paul, I. H., Heider, F., \& Gardner, R. W. (1959). Psychological issues ～(Vol. 1). International Universities Press.

Erikson, E. H. (1963). Youth: Change and challenge. Basic books. 
Eysenck, S. B. J., \& McGurk, B. J. (1980). Impulsiveness and venturesomeness in a detention center population. Psychological Reports, 47, 1299 - 1306.

Festinger, L. (1954). A Theory of Social Comparison Processes. Sage journals, 7(2), 117-140. doi.org/10.1177/001872675400700202.

Frick, P. (2007). Using the construct of psychopathy to understand antisocial and violent youth. In F. Herve \& J. Yuille (Eds.), The psychopath: Theory, research, and practice (pp. 343368). Mahwah, NJ: Erlbaum.

Gendreau, P., Goggin, C., \& Smith, P. (2002). "Is the PCL-R really the "unparalleled" measure of offender risk? A lesson in knowledge cumulation", Criminal Justice and Behavior, Vol. 29, pp. 397-426.

Goffman, E. (1963). Stigma: Notes on the management of spoiled identity. New York, NY: Simon \& Schuster.

Goffman, E. (1990). The presentation of self in everyday life. London, United Kingdom: Penguin.

Häkkänen-Nyholm, H., \& Hare, R. D. (2009). "Psychopathy, homicide, and the courts working the system", Criminal Justice and Behavior, Vol. 36 No. 8, pp. 761-777

Hare, R. D. (2003). Manual for the Revised Psychopathy Checklist (2ndEd.). Toronto, ON: Multi-Health Systems.

Hare, R. D., \& Neumann, C. S. (2008). Psychopathy as a clinical and empirical construct. Annual Review of Clinical Psychology, 4, 217-246. doi:10.1146/annurev.clinpsy. 3.022806 .091452 . 
Higgins, E. T. (1987). Self-discrepancy: A theory relating self and affect. Psychological Review, 94(3), 319-340. doi:10.1037/0033-295X.94.3.319.

Hirschi, T. (1969). Causes of Delinquency. Berkeley: University of California Press.

Hogg, Michael A. (2001). A social identity theory of leadership. Personality and Social Psychology Review, 5, 184-200. doi: 10.1207/S15327957PSPR0503_1.

Holsinger, A. M. (1999). Assessing criminal thinking: Attitudes and orientations influence behavior. Lanham: American Correctional Association, Inc.

Ingram, J. R., Patchin, J. W., Huebner, B. M., McCluskey, J. D., \& Bynum, T. S. (2007). Parents, friends, and serious delinquency: An examination of direct and indirect effects among atrisk early adolescents. Criminal Justice Review, 32(4), 380-400. doi:10.1177/0734016807311436.

Jackson, L. A., Sullivan, L. A., Harnish, R., \& Hodge, C. N. (1996). Achieving positive social identity: Social mobility, social creativity, and permeability of group boundaries. Journal of Personality and Social Psychology, 70(2), 241. doi:10.1037/0022-3514.70.2.241.

Juvonen, J. (1991). Deviance, perceived responsibility, and negative peer reactions. Developmental Psychology 27, 672-681. doi:10.1037/0012-1649.27.4.672.

Kiesner, J., Cadinu, M., Poulin, F., \& Bucci, M. (2002). Group identification in early adolescence: Its relation with peer adjustment and its moderator effect on peer influence. Child Development, 73(1), 196-208. Retrieved from http://www.jstor.org/stable/3696439

Kline, P. (2005). An easy guide to factor analysis. Routledge, New York. 
Laird, R. D., Jordan, K. Y., Dodge, K. A., Pettit, G. S., \& Bates, J. E. (2001). Peer rejection in childhood, involvement with antisocial peers in early adolescence, and the development of externalizing behavior problems. Development and Psychopathology, 13, 337-354.

Laurell, J., \& Dåderman, A. M. (2007), "Psychopathy (PCL-R) in a forensic psychiatric sample of homicide offenders: Some reliability issues", International journal of law and psychiatry, Vol. 30, No. 2, pp. 127-135

Mikami, A. Y., Boucher, M. A., \& Humphreys, K. (2005). Prevention of peer rejection through a classroom-level intervention in middle school. The Journal of Primary Prevention, 26(1), 5-23. doi:10.1007/s10935-004-0988-7

Mills, J. F., \& Kroner, D. G. (1999). Measures of Criminal Attitudes and Associates (MCAA). Unpublished instrument and user guide.

Mills, J. F., Anderson, D., \& Kroner, D. G. (2004). The antisocial attitudes and associates of sex offenders. Criminal Behaviour and Mental Health, 14(2), 134-145. doi:10.1002/ cbm.578

Mills, J. F., Kroner, D. G., \& Forth, A. E. (2002). Measures of criminal attitudes and associates (MCAA): Development, factor structure, reliability, and validity. Assessment, 9(3), 240253. doi:10.1177/1073191102009003003

Newman, B.M., Lohman, B.J., \& Newman, P.R. (2007). Peer group membership and a sense of belonging: their relationship to adolescent behavior problems. Adolescence, 42(166), 241-263. 
Nicholls, T. L., Ogloff, J. R., Brink, J., \& Spidel, A. (2005), "Psychopathy in women: A review of its clinical usefulness for assessing risk for aggression and criminality", Behavioral sciences and the law, Vol. 23 No. 6, pp. 779-802.

Parker, J. G., \& Asher, S. R. (1987). Peer relations and later personal adjustment: Are low-accepted children at risk? Psychological Bulletin 102(3):357-389. doi:10.1037/00332909.102.3.357

Paulhus, D. L., Neumann, C. S., \& Hare, R. D. (2015). Manual for the Self-Report Psychopathy Scale, 4th. Toronto, Ontario, Canada: Multi-Health Systems.

Rubin, M., \& Hewstone, M. (1998). Social identity theory's self esteem hypothesis: A review and some suggestions for clarification. Personality and Social Psychology Review, 2, 40-62.

Salekin, R. T., Rogers, R., \& Sewell, K. W. (1996). "A review and meta analysis of the Psychopathy Checklist and Psychopathy Checklist Revised: Predictive validity of dangerousness", Clinical Psychology: Science and Practice, Vol. 3 No. 3, pp. 203215.

Salovey, P., \& Rodin, J. (1984). Some antecedents and consequences of social-comparison jealousy. Journal of Personality and Social Psychology,47(4), 780-792. doi:10.1037/0022-3514.47.4.780

Shaw, J. M., \& Scott, W. A. (1991). Influence of parent discipline style on delinquent behaviour: The mediating role of control orientation. Australian Journal of Psychology, 43(2), 61-67. doi:10.1080/00049539108259101.

Sherretts, N., Boduszek, D., \& Debowska, A. (2016). Exposure to criminal environment and criminal social identity in a sample of adult prisoners: The moderating role of 
psychopathic traits. Law and Human Behavior, 40(4), 430-439. doi.org/10.1037/lhb0000188.

Simons, R. L., Whitbeck, L. B., Conger, R. D., \& Conger, K. J. (1991). Parenting factors, social skills, and value commitments as precursors to school failure, involvement with deviant peers, and delinquent behavior. Journal of Youth and Adolescence, 20(6), 645-664. doi:10.1007/BF01537367.

Spink, A., Boduszek, D., Debowska, A., \& Bale, C. (2018). Validation of the measure of delinquent social identity among youth offenders in the UK. Deviant Behavior, , 1-12. doi:10.1080/01639625.2018.1456723

Steiger, J. H. (1990). Structural model evaluation and modification: An interval estimation approach. Multivariate Behavioral Research, 25(2), 173-180. doi:10.1207/s15327906mbr2502_4

Strand, S., \& Belfrage, H. (2005). Gender Differences in Psychopathy in a Swedish Offender Sample. Behavioral Sciences and the Law Behav. Sci. Law 23: 837-850

Stryker, S., \& Burke, P. J. (2000). The past, present, and future of an identity theory. Social Psychology Quarterly, 63(4), 284-297.

Tajfel, H. (1978). Differentiation between social groups: Studies in the social psychology of intergroup relations. London, England: Academic Press.

Tajfel, H., \& Turner, J. (1979). An integrative theory of intergroup conflict. In W. Austin \& S. Worchel (Eds.), The social psychology of intergroup relations (pp. 33-47). Monterey, CA: Brooks/Cole. 
Thornberry, T., Krohn, M., Lizotte, A., \& Chard-Wierschem, D., (1993). The Role of Juvenile Gangs in Facilitating Delinquent Behavior. Journal of Research in Crime and Delinquency, 30, 55-87.

Tucker, L.R., \& Lewis, C. (1973). A reliability coefficient for maximum likelihood factor analysis. Psychometrika, 38, 1-10.

Turner, J. C. (1982). Towards a cognitive redefinition of the social group. In H. Tajfel (Ed.), Social Identity and Intergroup Relations. Cambridge: Cambridge University Press.

Turner, J. C., Hogg, M. A., Oakes, P. J., Reicher, S. D., \& Wetherell, M. S. (1987). Rediscovering the social groups: A self-categorization theory. Oxford: Blackwell.

Turner, J. C., Oakes, P. J., Haslam, S. A. \& McGarty, C. A. (1994). Self and collective: Cognition and social context. Personality and Social Psychology Bulletin, 20(5), 454463. Doi.org/10.1177/0146167294205002

Vryan, K.D., Adler, P.A., \& Adler, P. (2003). Identity. In L.T. Reynolds \& N.J. Herman- Kinney (Eds.), Handbook of symbolic interactionism (pp. 367-390). Lanham, MD: AltaMira Press.

Walters, G. D. (2003). Changes in criminal thinking and identity in novice and experienced inmates: Prisonization revisited. Criminal Justice and Behavior, 30(4), 399-421. doi:10.1177/0093854803253137.

Waterman, A. S. (1985). Identity in the Context of Adolescent Psychology. New Directions for Child Development., 30, San Francisco: Josey-Bass. 
Table 1. Descriptive Statistics for males and females for the MDSI Factors, Criminal Friends Index, Attitudes, Self-esteem, Rejection, Parental Attachment and Parental Supervision

\begin{tabular}{|c|c|c|c|c|c|c|c|c|c|c|c|}
\hline \multirow[b]{2}{*}{ Variables } & \multicolumn{5}{|c|}{ Boys } & \multicolumn{5}{|c|}{ Girls } & \multirow[b]{2}{*}{ t-value } \\
\hline & $M$ & $S D$ & $M d n$ & Min. & Max. & $M$ & $S D$ & $M d n$ & Min. & Max. & \\
\hline Cognitive centrality & 13.79 & 2.97 & 14 & 5 & 20 & 13.61 & 3.10 & 14 & 5 & 20 & 0.66 \\
\hline In-group affect & 13.86 & 2.65 & 14 & 5 & 20 & 13.69 & 2.78 & 14 & 5 & 20 & 0.72 \\
\hline In-group ties & 14.57 & 3.02 & 15 & 5 & 20 & 14.30 & 3.14 & 15 & 5 & 20 & 0.99 \\
\hline Criminal Friends Index & 19.72 & 5.54 & 20 & 4 & 33 & 18.72 & 5.85 & 19 & 4 & 33 & $1.95^{*}$ \\
\hline Criminal Attitudes & 13.34 & 2.28 & 13 & 7 & 18 & 13.26 & 2.30 & 13 & 7 & 18 & 0.38 \\
\hline Self-esteem & 15.55 & 2.76 & 15 & 7 & 22 & 15.76 & 2.68 & 16 & 7 & 22 & -0.87 \\
\hline Peer Rejection & 11.51 & 2.34 & 11 & 6 & 19 & 11.52 & 2.34 & 11 & 6 & 19 & -0.02 \\
\hline Parental Attachment & 19.69 & 5.92 & 18 & 9 & 36 & 19.71 & 6.24 & 18 & 9 & 36 & -0.04 \\
\hline Parental Supervision & 12.30 & 4.31 & 12 & 6 & 24 & 12.27 & 4.37 & 12 & 6 & 24 & 0.09 \\
\hline Affective Responsiveness & 2.63 & 1.31 & 3 & 0 & 5 & 2.52 & 1.28 & 3 & 0 & 5 & 0.96 \\
\hline Cognitive Responsiveness & 2.55 & 1.28 & 2 & 0 & 5 & 2.78 & 1.34 & 3 & 0 & 5 & $-1.93 *$ \\
\hline Interpersonal Manipulation & 2.68 & 1.40 & 3 & 0 & 5 & 2.47 & 1.41 & 2 & 0 & 5 & 1.69 \\
\hline Egocentricity & 3.18 & 1.35 & 3 & 0 & 5 & 3.19 & 1.23 & 3 & 0 & 5 & -0.06 \\
\hline
\end{tabular}


Table 2. Direct regression weights (and Standard Errors) for boys and girls

\begin{tabular}{|c|c|c|c|c|}
\hline \multirow[b]{2}{*}{ Variables } & \multicolumn{2}{|c|}{ Boys } & \multicolumn{2}{|c|}{ Girls } \\
\hline & $\beta$ & $S E$ & $\beta$ & $S E$ \\
\hline Peer Rejection $(\mathrm{REJ}) \Rightarrow$ Criminal Friends Index $(\mathrm{CFI})$ & -.18 & .12 & -.10 & .17 \\
\hline Parental Attachment (ATT) $\Rightarrow$ Criminal Friends Index & .16 & .12 & -.05 & .16 \\
\hline Parental Supervision (SUP) $\Rightarrow$ Criminal Friends Index & $-.19 * *$ & .08 & $-.19 *$ & .11 \\
\hline Living with parents (PAR) $\Rightarrow$ Criminal Friends Index & .09 & .07 & $-.20 *$ & .10 \\
\hline Living without parents (NO) $\Rightarrow$ Criminal Friends Index & .08 & .07 & .07 & .10 \\
\hline Criminal Friends Index $\Rightarrow$ Criminal Attitudes (ATTI) & -.10 & .08 & .06 & .10 \\
\hline Criminal Friends Index $\Rightarrow$ Cognitive Centrality $(C)$ & .02 & .04 & -.02 & .07 \\
\hline Criminal Friends Index $\Rightarrow$ In-group Affect (A) & -.01 & .04 & -.02 & .06 \\
\hline Criminal Friends Index $\Rightarrow$ In-group Ties $(\mathrm{T})$ & $.15^{*}$ & .07 & .12 & .09 \\
\hline Self-esteem (SE) $\Rightarrow$ Cognitive Centrality & $-.13 *$ & .04 & -.11 & .07 \\
\hline Self-esteem $\Rightarrow$ In-group Affect & -.03 & .04 & -.04 & .06 \\
\hline Self-esteem $\Rightarrow$ In-group Ties & $.42 * * *$ & .06 & $.50 * * *$ & .08 \\
\hline Affective Responsiveness (AR) $\Rightarrow$ Cognitive Centrality & .02 & .04 & .01 & .07 \\
\hline Affective Responsiveness $\Rightarrow$ In-group Affect & -.01 & .04 & .05 & .06 \\
\hline Affective Responsiveness $\Rightarrow$ In-group Ties & -.01 & .06 & $-.25 * *$ & .09 \\
\hline Cognitive Responsiveness (CR) $\Rightarrow$ Cognitive Centrality & .01 & .04 & -.04 & .06 \\
\hline Cognitive Responsiveness $\Rightarrow$ In-group Affect & .02 & .04 & -.01 & .06 \\
\hline Cognitive Responsiveness $\Rightarrow$ In-group Ties & - & .06 & $-.18 *$ & .08 \\
\hline Interpersonal Manipulation (IPM) $\Rightarrow$ Cognitive Centrality & .07 & .04 & -.02 & .07 \\
\hline Interpersonal Manipulation $\Rightarrow$ In-group Affect & $.08^{*}$ & .04 & .04 & .06 \\
\hline Interpersonal Manipulation $\Rightarrow$ In-group Ties & .06 & .06 & $.21 *$ & .09 \\
\hline Egocentricity $(\mathrm{E}) \Rightarrow$ Cognitive Centrality & $.84 * * *$ & .03 & $.80 * * *$ & .04 \\
\hline Egocentricity $\Rightarrow$ In-group Affect & $.87 * * *$ & .02 & $.82 * * *$ & .04 \\
\hline
\end{tabular}


1

2

3

4

5

6

7

8

9

10

11

12

13

14

15

16

17

18

19

20

21

22

23

24

25

26

27

28

29

30

31

32

33

34

35

36

37

38

39

40

41

42

43

44

45

46

47

48

49

50

51

52

53

54

55

56

57

58

59

60

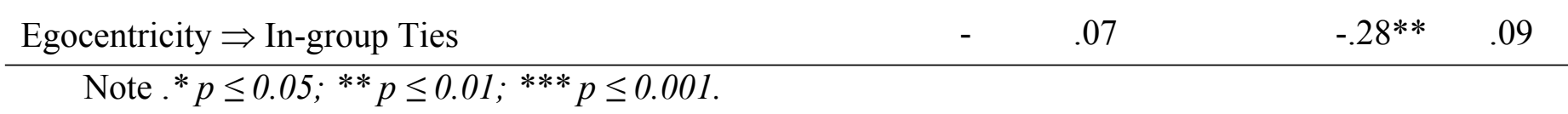




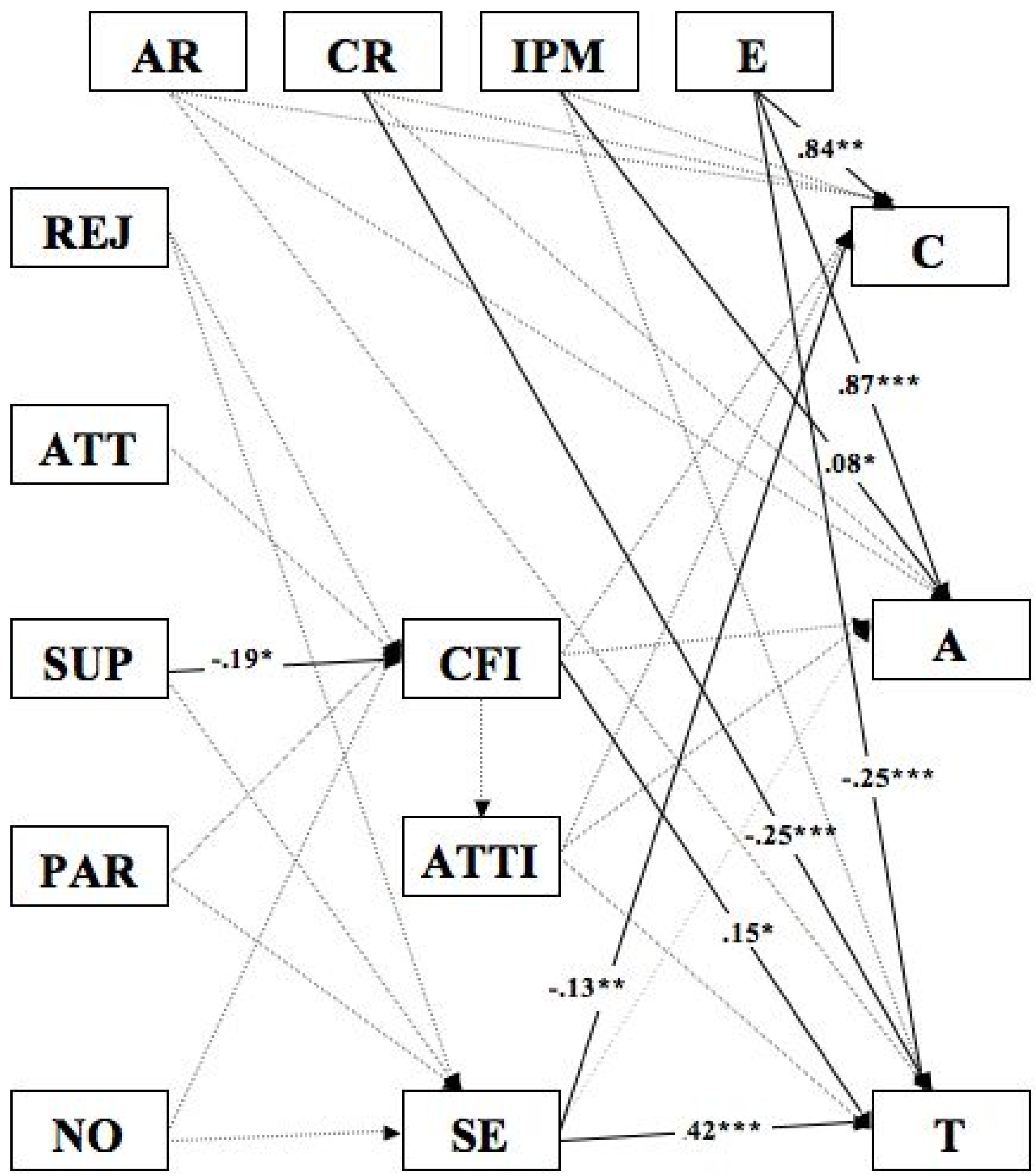

Figure 1. Path analysis of the MDSI for boys $(\mathrm{C}=$ Cognitive centrality; $\mathrm{A}=\mathrm{In}$-group affect; $\mathrm{T}$ $=$ In-group ties; $\mathrm{CFI}=$ Criminal Friends Index; ATTI = Criminal Attitudes; $\mathrm{SE}=$ Self-esteem; REJ $=$ Rejection; $\mathrm{ATT}=$ Parental attachment; $\mathrm{SUP}=$ Parental supervision; $\mathrm{PAR}=$ Parent; $\mathrm{NO}=$ 
No parent; $\mathrm{AR}=$ Affective responsiveness; $\mathrm{CR}=$ Cognitive responsiveness; $\mathrm{IM}=$ Interpersonal manipulation; $\mathrm{E}=$ Egocentricity).
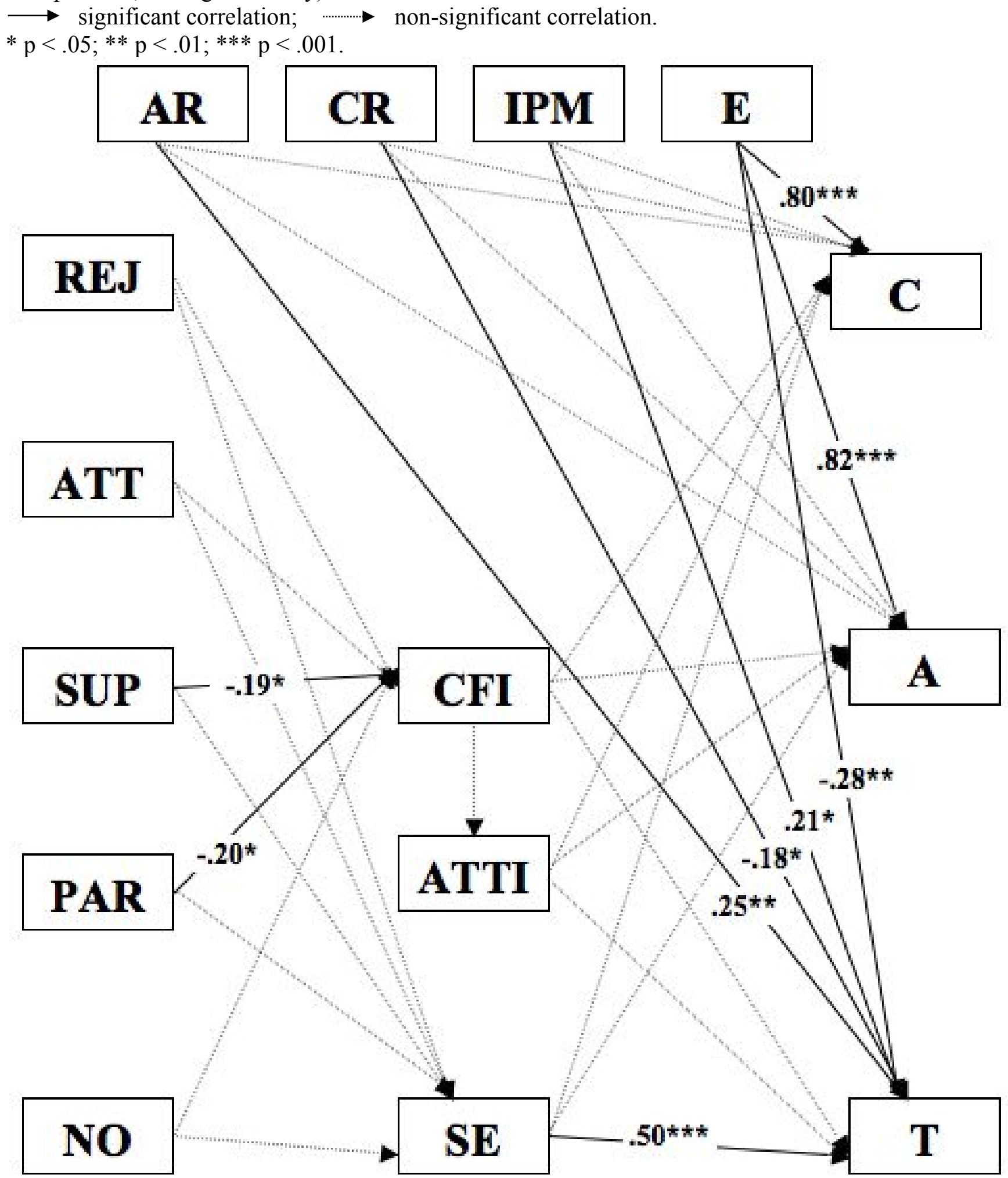
Figure 2. Path analysis of the MDSI for girls $(\mathrm{C}=$ Cognitive centrality; $\mathrm{A}=\mathrm{In}$-group affect; $\mathrm{T}$ $=$ In-group ties; $\mathrm{CFI}=$ Criminal Friends Index; ATTI $=$ Criminal Attitudes; $\mathrm{SE}=$ Self-esteem; REJ = Rejection; ATT $=$ Parental attachment; $\mathrm{SUP}=$ Parental supervision; $\mathrm{PAR}=$ Parent; $\mathrm{NO}=$ No parent; $\mathrm{AR}=\mathrm{Affective}$ responsiveness; $\mathrm{CR}=$ Cognitive responsiveness; $\mathrm{IM}=$ Interpersonal manipulation; $\mathrm{E}=$ Egocentricity).

$\longrightarrow$ significant correlation; $\rightarrow$. $\rightarrow$ non-significant correlation.

$* \mathrm{p}<.05 ; * * \mathrm{p}<.01 ; * * * \mathrm{p}<.001$. 